\title{
Assessment And Optimization Of The Interspace Dose Rate Of The Diagnostics Equatorial Port Plug \#3 In ITER With Attila*
}

\author{
M. Z. Youssef ${ }^{1}$, R. E. Feder ${ }^{2}$ \\ ${ }^{1}$ Mechanical and Aerospace Engineering Department, UCLA, Los Angeles, CA 90025 \\ ${ }^{2}$ Princeton Plasma Physics Lab, US Rte. 1 North @ Sayre Drive, Princeton, NJ 08542n \\ Corresponding author e-mail: Youssef@fusion.ucla.edu
}

\begin{abstract}
According to ITER integration procurement arrangements, the installment of diagnostics in a port should not increase the shutdown dose rate (SDDR) in the port interspace area by no more than $\sim 50 \mathrm{microSv} / \mathrm{hr}$ above the baseline, assuming another $50 \mathrm{microSv} / \mathrm{hr}$ is attributed to contribution from the port structure and other ITER in-vessel components, such that the upper SDDR limit of $100 \mathrm{microSv} / \mathrm{hr}$ is not exceeded $10^{6} \mathrm{~s}$ after shutdown. It was found that placing the initial design of the Motional Stark Effect, MSE, and the Charge Exchange Recombination Spectroscopy, CXRS, in the equatorial port \#3 (EPP3) resulted in an increase in the SDDR that far exceeded the limit. When we follow the optimization process discussed in this paper, substantial reduction in the port interspace SDDR was achieved. The results of the present work show that even when we combine the optimized CXRS and MSE diagnostics with a third GDC diagnostic, the excess of the SDDR over the baseline value did not exceed the allowed upper limit. The present work is based on utilizing the 3-D CAD-based Attila code for assessing the SDDR.
\end{abstract}

Keywords-Shutdown Dose Rate; Neutronics; 3-D nuclear Analysis, CXRS and MSE diagnostics; Optimization

\section{INTRODUCTION}

The Motional Stark Effect, MSE, and the Charge Exchange Recombination Spectroscopy, CXRS, will be housed in the equatorial port \#3 (EPP3) in ITER. The presence of these diagnostics leads to inter mangling labyrinths through which neutrons and gamma rays stream to the closure back plate and raise the decay dose rate inside the ports interspace (PI) areas where maintenance is performed. The design of the plugs calls for maintaining a shutdown dose rate (SDDR) in these areas not to exceed $100 \mu \mathrm{Sv} / \mathrm{hr} 10^{6} \mathrm{sec}(\sim 2$ weeks) after shutdown [1]. Maintaining this level of radiation is a very challenging task since the contribution to this radiation from in-vessel components other than the EPP3 is significant and cross-taking between these components is unavoidable. On the other hand, the diagnostics design team should ensure that maximizing the shielding capability of the EPP3 should not be on the expense of the proper functionality and throughput of the installed diagnostics. In order to move forward with the diagnostic systems optimization, we followed in the present work the design guidance provided in the "Interface Technical Note" [2-3] of the port integration procurement arrangements (this technical note is written for EPP9 but we assume it applies as well to EPP3). It is required that port integrators should perform the neutronics analysis of an integrated model of the port shielding including all diagnostics located in the port. The contribution from each diagnostic is determined with all other apertures closed. The allocation given to the environment and the port plug under consideration is $\sim 50$ $\mu \mathrm{Sv} / \mathrm{hr}$. The allocation for all the diagnostics installed in the port should not exceed the balance such that the total port interspace SDDR is maintained at $100 \mu \mathrm{Sv} / \mathrm{hr} \max$. There are three vertical shield modules that house the diagnostics in EPP3. Therefore, the allocation allowed for each diagnostic should not exceed $\sim 17 \mu \mathrm{Sv} / \mathrm{hr}$. The objective of the present work is to investigate whether or not these guidelines are maintained and the upper allocation limits for SDDR are not exceeded when the CXRS and MSE diagnostics are installed in the EPP3, with possibly an additional third diagnostic. As reported here, it is shown that the initial design specifications of these two diagnostics led to a substantial increase in the PISDDR over the baseline EPP3 (with no diagnostics installed). Optimization of these diagnostics (in terms of selection of its configurations and dimensions) was an urgent task which was undertaken, following the procedures discussed in this paper, in order to ensure that the upper SDDR allocation is not exceeded without undermining the functionality of these diagnostics.

The modeling and the calculation procedures followed in the preset work is described in Section II. The specifications and performance of the reference baseline EPP3, the assumptions used in deriving the port interspace SDDR, and the calculation procedures followed are outlined in this Section. Section III is devoted to the results from the present study where we give the PI-SDDR attainable in the baseline EPP3, the PI-SDDR for the un-optimized combined MSE and CXRS diagnostics case, and the results of a parametric study to demonstrate the dependency of the PI-SDDR on the geometry of a typical labyrinth of an MSE or CXRS diagnostic. The 
outcomes from this optimization study were used in designing the latest MSE and CXRS diagnostics. The results from each optimized diagnostic when placed alone in the EPP3 are also given in given in Sections III along with the case of installing three diagnostics. Finally we cite in Section IV the conclusions from the present study.

\section{MODELING AND CALCULATION BACKGROUND}

\section{A. Reference Baseline Equatorial Port Plug \#3(EPP3)}

The geometrical arrangement of the baseline EPP3 is the same as the Global Equatorial Port Plug (GEPP) described in Ref. 4 and is shown in Fig. 1. It consists of three vertical drawers (diagnostics shield modules, DSM) which house the major parts of the diagnostics. There are two 5-mm stepped gaps [4] between the drawers. The diagnostics shield block (DSB) and the diagnostics first wall (DFW) precede the DSMs. A generic port plug structure box, 16.5 US tones in weight, houses the EPP3 and a 20-mm gap is maintained between the port plug and the vacuum vessel. To reduce the SDDR in the port inter space, a $10-\mathrm{mm}$ labyrinth is introduced in this $20-\mathrm{mm}$ gap. The 5-mm stepped (railed) gaps and the 10-mm labyrinth were introduced to minimize neutron streaming from the plasma [4].

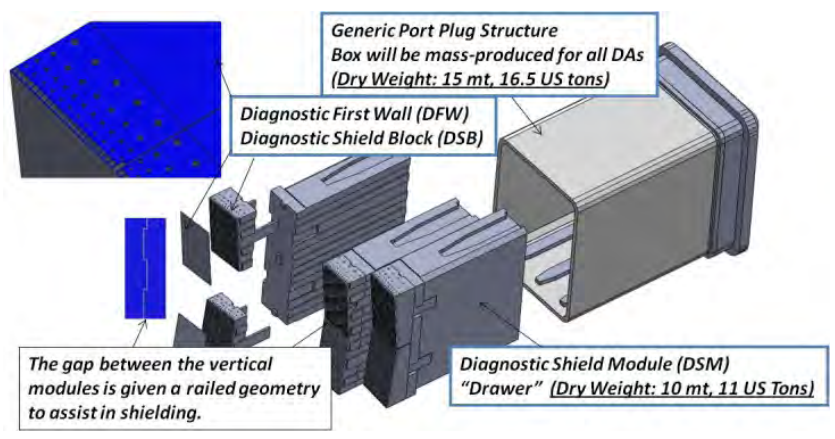

Fig. 1: Components of the generic equatorial port plug (GEPP)

\section{B. Calculation Model and Assumptions Applied}

In contrast to the full ITER 20-degree B-Lite model used in previous studies [4-5], a simplified 20-degree ITER model is used in the present calculations and is shown in Fig. 2. The upper and lower ports are deliberately excluded from the model in order to investigate how much increase in the PI-SDDR is realized upon only integrating the diagnostics in the equatorial port. However, all the geometrical details at the FW of the EPP3 and its surroundings (i.e. all in-vessel blanket, in-vessel coils and piping) are retained in the model in order to generate the actual wall loading at the FW of the EPP3. Thus, according to the vacuum boundary conditions (BQs) considered at the outer boundaries, neutrons that reach the outer vacuum vessel boundary which are coming from areas other than the EPP3 are killed. The albedo white BCs applied at the sides of the 20-degree model is used to simulate the continuity of the EPP3 in the toroidal direction [4].

In the simplified calculation model no shielding materials were considered in the port interspace area. Only the Interspace
Support Structure (ISS) is accounted for in the model. No other diagnostics components are mounted on the ISS and the details of the remote handing rails are excluded from the model. Two other major assumptions are made in the present study (more details on these assumptions can be found in Ref. 6). They are:

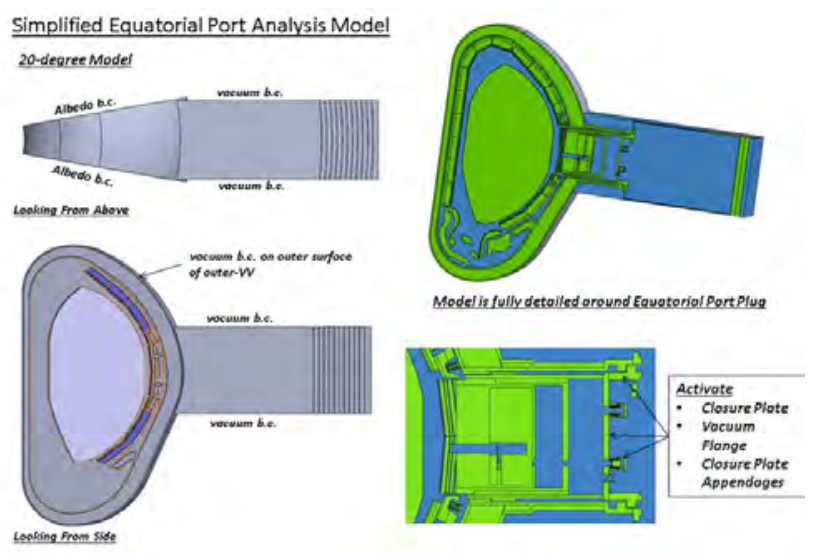

Fig. 2: Simplified ITER equatorial port model used in the calculation

1. The comparison among the several SDDR estimates reported here is made at a distance one meter away $(1-\mathrm{m})$ from the closure plate inside the PI area. These values have been averaged over a vertical and a horizontal lines extending from the ceiling to the floor and from one side to the other side of the PI room. This was an arbitrary choice which most likely will change once the ITER IO makes a decision on the tally size and location where SDDR comparisons are made (Note: most of the reported PI-SDDR calculated by other analysts [7] are based on averaging the Monte Carlo results over a large volume extending from the ceiling of the PI area down to its floor).

2. In calculating the interspace dose, only the port plug closure plate and vacuum flange are "activated". In other words, gamma photons from activated steel are only transported from the closure plate and flange. The activation of the surrounding interspace walls is not considered since this is dominated by neutrons from the upper and lower ports and leaking from the vacuum vessel. Furthermore, the direct impact of integrating a particular diagnostic in the DSM is to increase the neutron flux impinging on closure plate and emanating from the DSM as a result of neutrons streaming down its labyrinths. Therefore, the activation of these two components is a direct indicative of the impact of the diagnostics insertion in the EPP3.

\section{Calculation Procedures and Computational Tool and Parameters}

The 3-D, FEM, Discrete Ordinates code, ATTILA [8-9], has been utilized to undertake the required nuclear analysis. The serial version and the distributed memory parallel (DMP) version of ATTILA-7.1.0 and ATTILA-7.2.0 have been used along with the FENDL2.1/FORNAX and the ICRP-74 flux-todose conversion factor [10] data bases. The calculation 
procedures followed in assessing the SDDR are the same 3steps procedures we adopted in previous studies. The reader is referred to Refs. 4-6 for more details.

\section{RESULTS}

\section{A. The Baseline Equatorial Port Plug}

Figure 3 shows the contours of the neutron flux in the baseline EPP3. The upper left insert is a vertical cut passing through the middle DSM whereas a top view of a horizontal cut at $\mathrm{z}=30 \mathrm{~cm}$ is shown in the lower left insert. The flux at the bottom of the EPP3 is higher than the flux at the top because the entrance of the lower installation gap through which neutron are streaming out has a higher neutron wall load since it is closer to the plasma center. Contours of the flux at the front side of the closure plate (facing the plasma) and at the back side (inside the PI room) are shown respectively on the right side of the figure. The effect of neutrons streaming through the stepped 5-mm gaps between the vertical DSMs is evident in the figure.

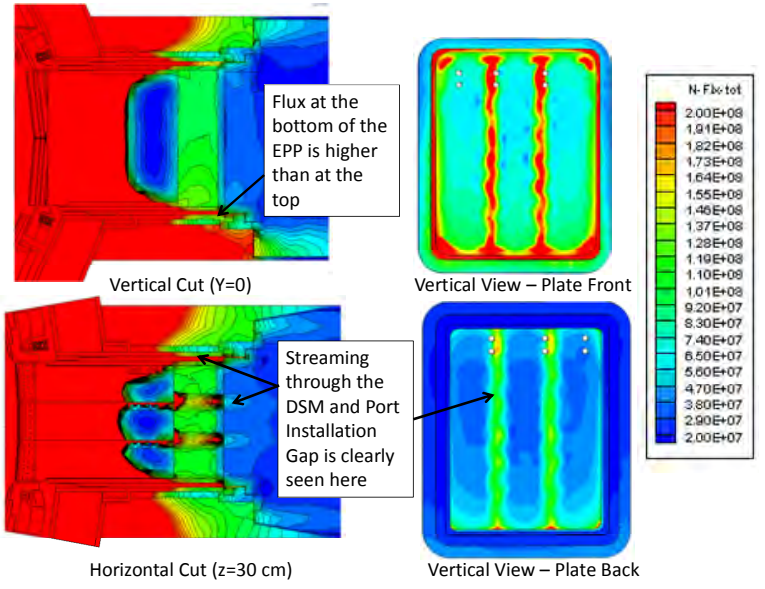

Fig. 3: Contour of neutron flux (n/cm2.s) in the baseline EPP3.

The contours of the corresponding SDDR are shown in Figs. 4 for the horizontal plane. Line 3 and 4 shown in the figure are located just behind the closure plate and at 1-m away from it. Line 1 and 2 (not shown) are the equivalent lines in the vertical plane. The SDDR at the center of line 2 and line 4 (located 1-m away from the closure plate) is $\sim 30 \mu \mathrm{Sv} / \mathrm{hr}$. This value is not the true SDDR at this location. Rather, it is the estimated value based on all the assumptions discussed in the previous section and against which the increase in the PISDDR is quantified upon installing the diagnostics in the port.

\section{B. Un-optimized MSE and CXRS Diagnostics Installed in EPP3}

Contours of the neutron flux in the vertical and horizontal planes described in Fig. 3 when the un-optimized MSE and CXRS diagnostics are inserted in the middle and the right DSM are shown in Fig. 5. Substantial increase in the interspace flux is obtained due to those neutrons escaping from their labyrinth channels. The neutron fluxes at the middle of line 1 and line 2 (in vertical plane) and at the middle of line 3 and line 4 (in horizontal plane) are $2.2 \mathrm{E} 9 \mathrm{n} / \mathrm{cm}^{2} . \mathrm{s}, 7.8 \mathrm{E} 8$ $\mathrm{n} / \mathrm{cm}^{2} . \mathrm{s}, 2.3 \mathrm{E} 9 \mathrm{n} / \mathrm{cm}^{2} . \mathrm{s}$, and $8.6 \mathrm{E} 8 \mathrm{n} / \mathrm{cm}^{2} . \mathrm{s}$, respectively. This represents an increase by a factor of $\sim 69, \sim 34, \sim 68$, and $\sim 35$ relative to the same locations in the baseline case. The corresponding SDDRs at these locations were found to be $1690 \mu \mathrm{Sv} / \mathrm{hr}, 1100 \mu \mathrm{Sv} / \mathrm{hr}, 1780 \mu \mathrm{Sv} / \mathrm{hr}$, and $1130 \mu \mathrm{Sv} / \mathrm{hr}$, respectively, which translates to an increase by a factor of $\sim 25, \sim 36, \sim 24$, and $\sim 38$, relative to the baseline case. The average SDDR along 2 and 4 in the baseline is $\sim 16 \mu \mathrm{Sv} / \mathrm{hr}$ whereas the average SDDR with the diagnostics installed is $\sim 580 \mu \mathrm{Sv} / \mathrm{hr}$ (average ratio of $\sim 36$ ). The average excess over the base line value was found to be $\sim 564 \mu \mathrm{Sv} / \mathrm{hr}$ which is far above the allocation of $\sim 34 \mu \mathrm{Sv} / \mathrm{hr}$ for both diagnostics (allocation of $\sim 17 \mu \mathrm{Sv} / \mathrm{hr}$ each, see Section I). This calls for the need to optimize the design of both diagnostics to reach the allocation limit allowed.

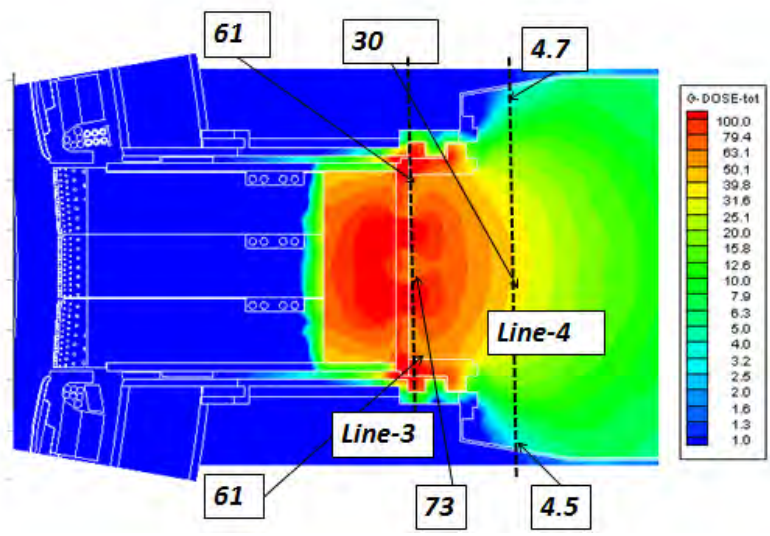

Fig. 4: Contour of SDDR ( $\mu \mathrm{Sv} / \mathrm{hr})$ in a horizontal plane at $\mathrm{z}=30 \mathrm{~cm}$ through the baseline EPP3
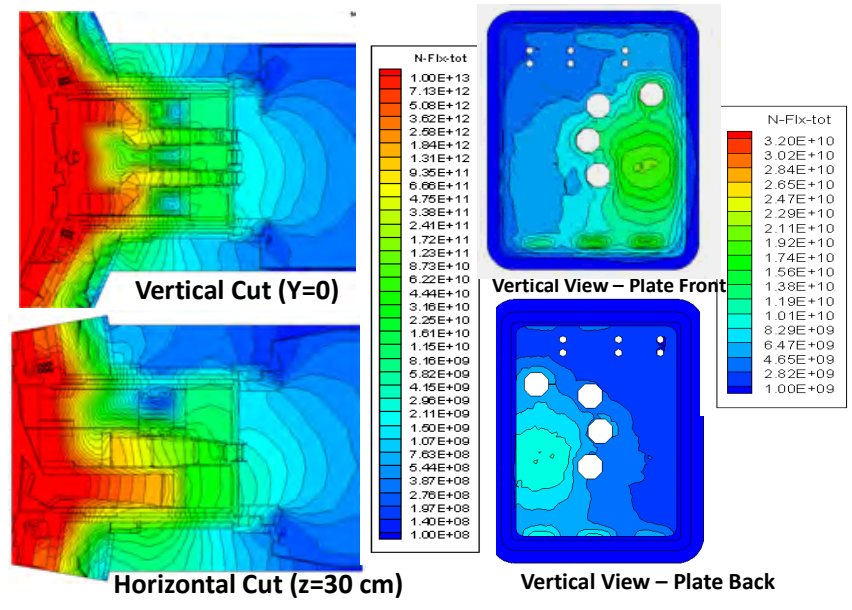

Fig. 5: Contour of neutron flux (n/cm2.s) with the MSE and CXRS diagnostincs (un-optimized) installed in the EPP3.

\section{Dependence of Neutron Flux at Back Plate on Dimensions and Location of Z-shaped Dogleg}

Both the MSE and CXRS diagnostics are characterized by having one or more Z-shaped labyrinth (penetration). The 
geometrical arrangement of the penetrations discussed in this parametric optimization study is given in Fig. 6 (taken from Refs. 11-12). Also shown are the simplified analytical expressions used for the various components of the neutron flux reaching the back plate. All parameters appearing in the analytical expressions are normalized to the distance D between the FW and back plate. The definition of the parameters shown are as follows:

$x=$ position of the dogleg behind the FW

$\lambda=$ mean free path through the shield

$\theta=$ angle of the middle leg with the vertical,

$\mathrm{d}=$ vertical distance between the upper and lower sections,

$a_{i}=$ cross sectional areas of each of the sections,

$\eta_{\mathrm{i}}=$ neutron albedo of the mirrors.

Typical initial values of the parameters used are: $\lambda=6 \mathrm{~cm}, \theta=60^{\circ}, \mathrm{d}=30.11 \mathrm{~cm}, \mathrm{a}_{1}=817 \mathrm{~cm}^{2}, \mathrm{a}_{2}=311 \mathrm{~cm}^{2}$, $\mathrm{a}_{3}=440 \mathrm{~cm}^{2}, \eta_{1}=\eta_{2}=0.95, \mathrm{D}=265 \mathrm{~cm}$, and $\mathrm{A}=38,385 \mathrm{~cm}^{2}$

$$
\begin{aligned}
& \Phi_{\text {tot }}=\text { Average flux at the back plate obtained } \\
& \text { by a weighted sum of } \Phi_{1} \Phi_{2, \text { and }} \Phi_{3} \\
& \phi_{\text {tot }}=\left(a_{1} \phi_{1}+a_{2} \phi_{2}+a_{3} \phi_{3}\right) / A \\
& \text { where } \mathrm{A} \text { is the total surface area of the back plate }
\end{aligned}
$$

Fig.6: . Analytical model of a Z-shaped dogleg labyrinth and the analytical expressions for the various components of the neutron flux at the back plate. (Refs. 11-12)

The normalized flux of the neutrons streaming along the upper channel and reaching the back plate, $\mathrm{F} 1\left(\phi_{1}\right)$, is independent of $\mathrm{d}$ and $\theta$. It depends mainly on the distance $\mathrm{x}$. The larger the distance $\mathrm{x}$ is, the less efficient the region behind the upper streaming channel in attenuating the flux. Consequently, F1 increases as $\mathrm{x}$ increases. Maximum and minimum theoretical values of $\mathrm{F} 1$ is obtained when $\mathrm{x}=\mathrm{D}$ $(F 1=1)$ and when $x=0$, respectively. On the other hand, the neutron flux streaming through the lower channel, F2 $\left(\phi_{2}\right)$, has its maximum and minimum theoretical values when $\mathrm{x}=0$, $(F 2=1)$ and when $x=D$, respectively. Thus, the impact of the distance $\mathrm{x}$ on F1, and F2 has opposing effects. The scattered component of the flux, F3, depends on the values of $d$, $\theta$, $x$, and the cross-section areas $a_{2}$ and $a_{3}$. The total normalized flux, Ftot, is the sum of F1, F2, and F3, weighted by the corresponding cross sectional areas. The theoretical range of the Z-leg angle $\theta$ is taken as $\theta=0^{\circ}-90^{\circ}$

In Fig. 7, we depict the dependency of Ftot on $\theta 1$ for various values of $x$, ranging from $x=0.1$ to $x=1$. This figure reveals at what value of $\mathrm{x}$ and $\theta 1$ Ftot reaches its lowest value. Between $x=0$ and $x=0.2$ (actually $x=\sim 0.29$ ), there is no optimal $\theta 1$ (opt). In this range of small value of $x$, Ftot always increases with $\theta 1$, meaning that $\theta 1=0$ gives the lowest value of Ftot. Also, for a given $\theta 1$ in this low $\mathrm{x}$ range, increasing $\mathrm{x}$ leads to lower Ftot. Generally, and according to the values of the other parameters used, the lowest Ftot occurs at $\mathrm{x}=\sim 0.66$ with $\theta 1$ (opt) $=\sim 73^{\circ}$.

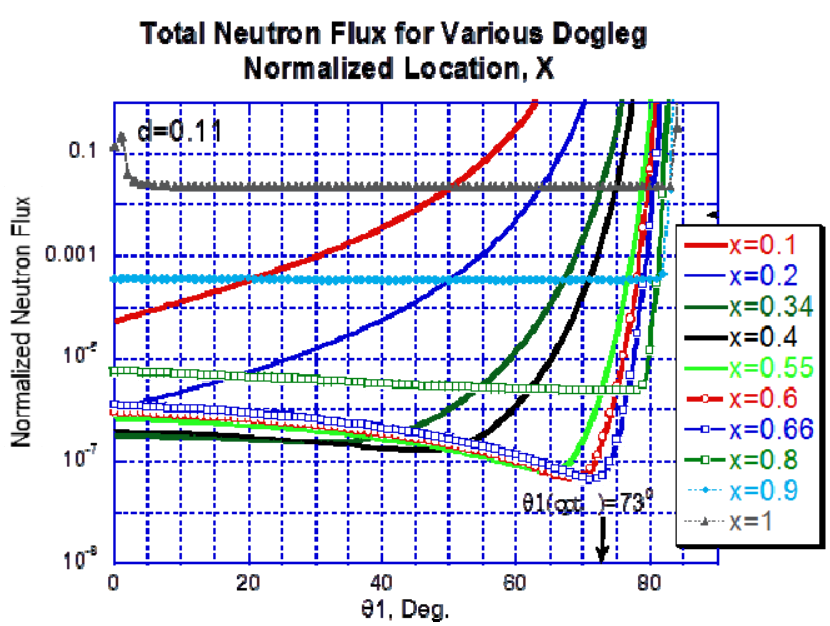

Fig. 7: Dependency of normalized total neutron flux on Z-leg angle $\theta 1$ for various dogleg normalized location $\mathrm{x}$ (normalized vertical distance $\mathrm{d}=0.11$ )

\section{Optimized CXRS Diagnostic Installed Alone in EPP3}

An optimized CXRS diagnostic was determined based on the optimization results given in previous subsection. It was placed in the middle DSM of EPP3 with no other diagnostics installed. Figure 8 shows the attainable neutron flux in the vertical and horizontal planes described earlier. The neutron fluxes at the middle of line 1 and line 2 and at the middle of line 3 and line 4 are $7.8 \mathrm{E} 7 \mathrm{n} / \mathrm{cm}^{2} . \mathrm{s}, 3.7 \mathrm{E} 7 \mathrm{n} / \mathrm{cm}^{2} . \mathrm{s}, 9.2 \mathrm{E} 7$ $\mathrm{n} / \mathrm{cm}^{2} . \mathrm{s}$, and $4.2 \mathrm{E} 7 \mathrm{n} / \mathrm{cm}^{2} . \mathrm{s}$, respectively. This represents an increase by only a factor of $\sim 2.4, \sim 1.6,2.7$, and $\sim 1.7$, respectively, relative to the same locations in the baseline case. The corresponding SDDRs in the horizontal plane are shown in Fig. 9. The SDDRs at the four locations described earlier are $139 \mu \mathrm{Sv} / \mathrm{hr}, 52 \mu \mathrm{Sv} / \mathrm{hr}, 150 \mu \mathrm{Sv} / \mathrm{hr}$, and $54 \mu \mathrm{Sv} / \mathrm{hr}$, respectively. The corresponding dose ratios to the baseline case are only $\sim 2, \sim 1.7, \sim 2$, and $\sim 1.8$, respectively.

\section{E. Optimized MSE Diagnostic Installed Alone in EPP3}

An optimized MSE diagnostic was also determined from the optimization study. Contours of the neutron flux in the vertical and horizontal plane are shown in Fig. 10. Note that the vertical cut is taken here at $y=-47 \mathrm{~cm}$ (the MSE diagnostic is installed in the right DSM). The fluxes at the middle of the equivalent line 1 and line 2 and at the middle of line 3 and line 4 are $6.3 \mathrm{E} 7 \mathrm{n} / \mathrm{cm}^{2} . \mathrm{s}, 3.2 \mathrm{E} 7, \mathrm{E} 7 \mathrm{n} / \mathrm{cm}^{2} . \mathrm{s}, 5.3 \mathrm{E} 7 \mathrm{n} / \mathrm{cm}^{2} . \mathrm{s}$, and 
$3.1 \mathrm{E} 7 \mathrm{n} / \mathrm{cm}^{2} . \mathrm{s}$, respectively. The flux ratios in this case are $\sim 2$, $\sim 1.4, \sim 1.6$, and $\sim 1.3$. The corresponding SDDRs in the vertical plane at $y=-47 \mathrm{~cm}$ are shown in Fig. 11 . The SDDRs at the key four locations are $116 \mu \mathrm{Sv} / \mathrm{hr}, 40 \mu \mathrm{Sv} / \mathrm{hr}, 107 \mu \mathrm{Sv} / \mathrm{hr}$, and 46 $\mu \mathrm{Sv} / \mathrm{hr}$, respectively. The corresponding dose ratios to the base line case are lower than those in the CXRS alone case and they are only $\sim 1.7, \sim 1.3, \sim 1.5$, and $\sim 1.5$, respectively.

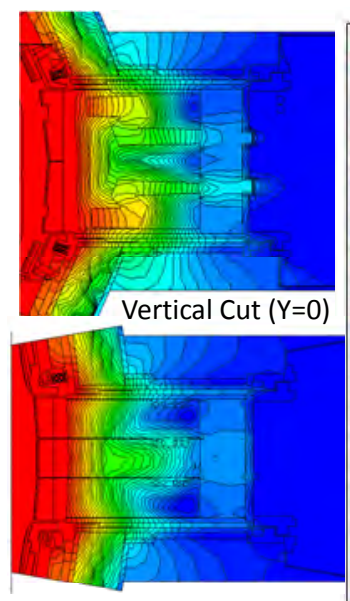

Horizontal Cut $(z=50 \mathrm{~cm})$

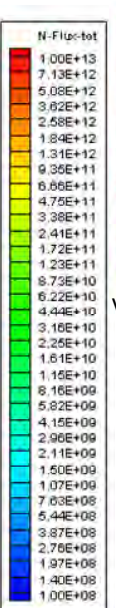

OOE +08

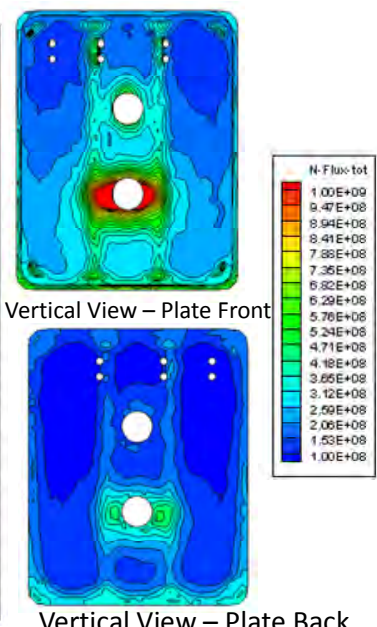

Vertical View - Plate Back
Fig. 8: Contour of neutron flux $(\mathrm{n} / \mathrm{cm} 2 . \mathrm{s})$ with an optimized CXRS diagnostic installed alone in EPP3.

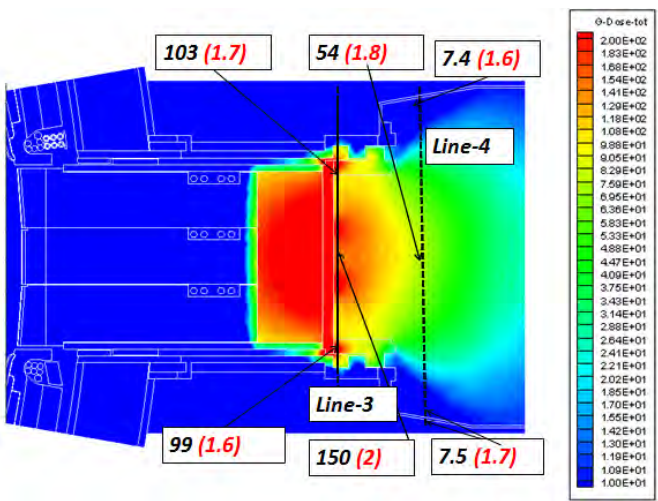

Fig. 9: Contour of SDDK ( $\mu \mathrm{Sv} / \mathrm{hr})$ in a horizontal plane at $\mathrm{z}=30$ with the optimized CXRS diagnostic installed alone in EPP3

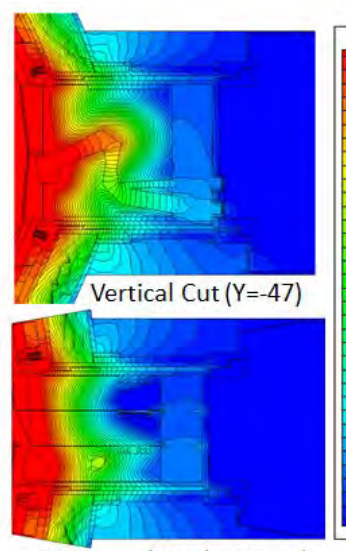

Horizontal Cut $(\mathrm{z}=50 \mathrm{~cm})$
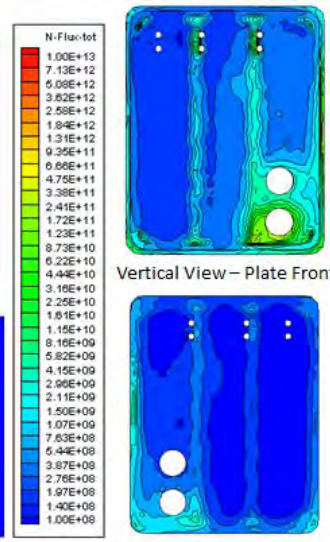

Vertical View - Plate Back
Fig. 10: Contour of neutron flux (n/cm2.s) with the optimized MSE diagnostic installed alone in EPP3

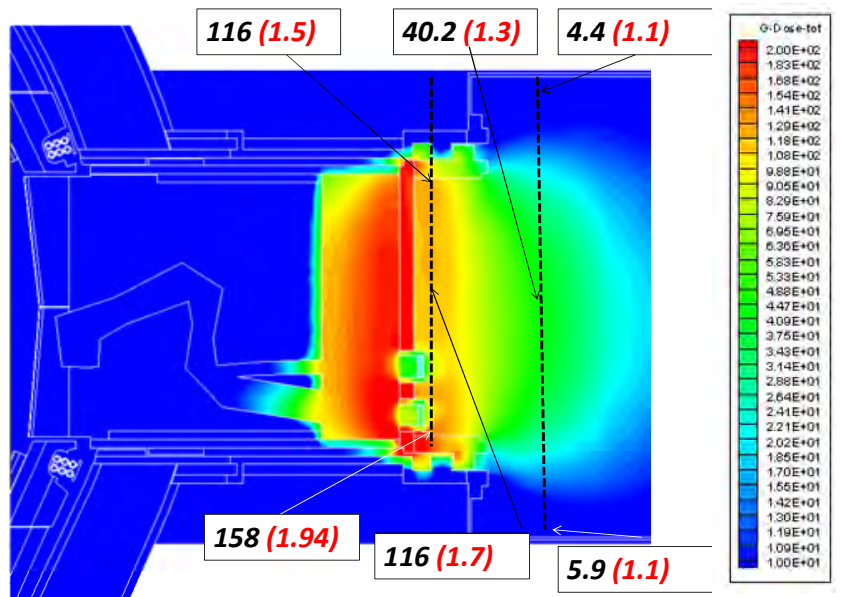

Fig. 11: Contour of SDDR $(\mu \mathrm{Sv} / \mathrm{hr})$ in a vertical plane at $\mathrm{y}=-47 \mathrm{~cm}$ with the optimized MSE diagnostic installed alone in EPP3

\section{F. Optimized CXRS, Optimized MSE, and GDC Diagnostics Installed EPP3}

In this configuration the optimized CXRS and MSE discussed above are combined in EPP3 along with an additional GDC diagnostic. With these three diagnostics installed, one is interested in examining if the installment of the three diagnostics leads to no more than the maximum allocation allowed of $\sim 50 \mu \mathrm{Sv} / \mathrm{hr}(\sim 17 \mu \mathrm{Sv} / \mathrm{hr}$ per diagnostic). Figures 12 depicts the contours of the SDDR in a vertical plane located at $y=-47$. The ratios to the corresponding values in the baseline are also shown. These ratios are in the range of 2-4 at 1-m away from the back plate. This is shown in Fig. 13 which depicts the SDDR contours on a vertical cut at this location where it is clear that SDDR increases in value as we move towards the middle locations.

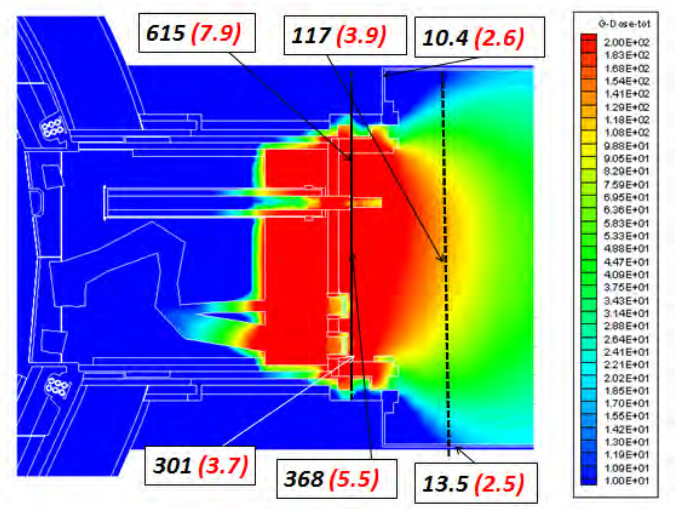

Fig. 12: Contour of SDDR $(\mu \mathrm{Sv} / \mathrm{hr})$ at a vertical plane at $\mathrm{y}=-47 \mathrm{~cm}$ with the optimized CXRS, optimized MSE, and GDC diagnostics installed in EP

Tables II summarizes the results discussed above for three configurations, namely: an optimized CXRS diagnostic alone, an optimized MSE diagnostic alone, and the combined configuration that includes the additional GDC diagnostic. The Table shows the SDDR at 10 locations along line 2 and line 4 described earlier. Point-average values are given along each line as well as along the two lines together. The excess over the baseline value is, on the average, $\sim 12 \mu \mathrm{Sv} / \mathrm{hr}$ and $\sim 8 \mu \mathrm{Sv} / \mathrm{hr}$ in 
the optimized CXRS alone and the optimized MSE alone configuration, respectively. These values are below the $\sim 17$ $\mu \mathrm{Sv} / \mathrm{hr}$ allocation limit per diagnostic. On the other hand, the excess over the baseline when the three diagnostics installed in EPP3 is $\sim 46 \mu \mathrm{Sv} / \mathrm{hr}$ which is also below the $\sim 50 \mu \mathrm{Sv} / \mathrm{hr}$ upper limit.

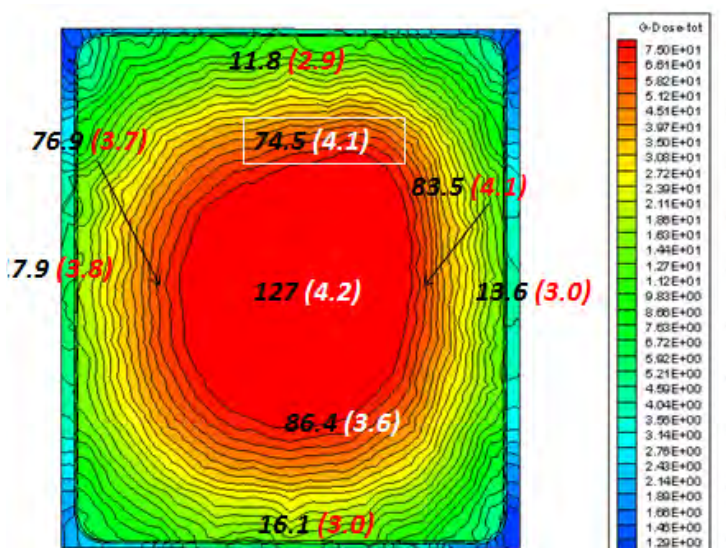

Fig. 13: Contour of SDDR $(\mu \mathrm{Sv} / \mathrm{hr})$ at a vertical cut located 1-m away from the closure plate with the optimized CXRS, optimized MSE, and GDC diagnostics installed in EPP3

Table II: Attainable SDDR ( $\mu \mathrm{Sv} / \mathrm{hr})$ and excess over the baseline values along line 2 and line 4 on a vertical plane located 1-m away from the closure plate for three diagnostics configurations

\begin{tabular}{|c|c|c|c|c|c|c|c|c|c|c|}
\hline \multirow{3}{*}{ Location } & \multirow{2}{*}{\multicolumn{3}{|c|}{$\begin{array}{l}\text { Coordinates } \\
\text { Location }(\mathrm{cm})\end{array}$}} & \multicolumn{4}{|c|}{ Shutdown Dose Rate, SDDR ( $\mu \mathrm{Sv} / \mathrm{hr})$} & \multicolumn{3}{|c|}{ Excess over baseline } \\
\hline & & & & \multirow{2}{*}{ Baseline } & \multirow{2}{*}{$\begin{array}{l}\text { CXRS } \\
\text { ONLY }\end{array}$} & \multirow{2}{*}{$\begin{array}{l}\text { MSE } \\
\text { ONLY } \\
\end{array}$} & \multirow{2}{*}{$\begin{array}{c}\text { CXRS+MSE } \\
+ \text { GDC }\end{array}$} & \multirow{2}{*}{$\begin{array}{l}\text { CXRS } \\
\text { ONLY } \\
\end{array}$} & \multirow{2}{*}{$\begin{array}{l}\text { MSE } \\
\text { ONLY }\end{array}$} & \multirow{2}{*}{$\begin{array}{c}\mathrm{CXRS}+\mathrm{MSE} \\
+\mathrm{GDC}\end{array}$} \\
\hline & $\mathrm{x}$ & $\mathrm{y}$ & $\mathrm{z}$ & & & & & & & \\
\hline \multirow{5}{*}{ Line 2} & 1222 & 0 & 230 & 4 & 6 & 5 & \begin{tabular}{|l|}
12 \\
\end{tabular} & 2 & 1 & 8 \\
\hline & 1222 & 0 & 146 & 18 & 30 & 28 & 75 & 12 & 9 & 56 \\
\hline & 1222 & 0 & 62 & 30 & 52 & 45 & 127 & 22 & 14 & 96 \\
\hline & 1222 & 0 & -22 & 24 & 43 & 35 & 86 & 19 & 12 & 63 \\
\hline & 1222 & 0 & -106 & 5 & 8 & 7 & 16 & 2 & 2 & 11 \\
\hline Average & & & & 16 & 28 & 24 & 63 & 11 & 8 & 47 \\
\hline \multirow{5}{*}{ Line 4} & 1222 & 142 & 30 & 5 & 7 & 8 & 18 & 3 & 3 & 13 \\
\hline & 1222 & 71 & 30 & 21 & 36 & 29 & 77 & 15 & 8 & 56 \\
\hline & 1222 & 0 & 30 & 30 & 54 & 46 & 119 & 24 & 16 & 89 \\
\hline & 1222 & -71 & 30 & 20 & 35 & 32 & 84 & 15 & 12 & 63 \\
\hline & 1222 & -142 & 30 & 5 & 8 & 7 & 14 & 3 & 2 & 9 \\
\hline Average & & & & 16 & 28 & 24 & 62 & 12 & 8 & 46 \\
\hline Both lines (av.) & & & & 16 & 28 & 24 & 63 & 12 & 8 & 46 \\
\hline
\end{tabular}

\section{CONCLUSIONS}

The initial design of the Motional Stark Effect (MSE) and the Charge Exchange Recombination Spectroscopy (CXRS) diagnostics show that, when they are installed in the equatorial port\#3 (EPP3), the shutdown dose rate in the port interspace PI-SDDR substantially increases. The excess of the SDDR over the baseline EPP3 value at location one meter (1-m) away from the closure plate is $\sim 564 \mu \mathrm{Sv} / \mathrm{hr}$ which is far above the allowed allocation of $\sim 34 \mu \mathrm{Sv} / \mathrm{hr}$ for both diagnostics (allocation of $\sim 17 \mu \mathrm{Sv} / \mathrm{hr}$ each, according to the guidance provided for the port integration procurement arrangements). This called for the need to optimize the diagnostics design in order to bring down the SDDR to the allowed upper limit. Upon undertaking this optimization task described in this paper, we were able to reduce the SDDR to an acceptable values. Even when a GDC diagnostic was added to the optimized CXRS and MSE diagnostics, the excess SDDR over the baseline value was found to be $\sim 48$ $\mu \mathrm{Sv} / \mathrm{hr}$ (less than the limit of $\sim 50 \mu \mathrm{Sv} / \mathrm{h}$ ). The results of the present analysis are based on a set of assumptions, some of which need further confirmation and agreement among ITER designers, guided by ITER-IO approval. For example, the dose in the port interspace averaged at locations 1-m away from the closure plate is considered to be the indicative of how much increase in the PI-SDDR occurs upon the diagnostics insertion in EPP3. Furthermore, it is assumed that neutrons streaming out of the diagnostics labyrinths are the major contributor to the activation of the closure plane and flange when other components (e.g. upper and lower ports) are excluded from the model used in the analysis. Accordingly, the local values cited here for the SDDR should not be considered as the true values. Rather, they are the estimated values against which the increase in the SDDR is quantified upon installing the diagnostics in EPP3.

*This work is funded by the Princeton Plasma Physics Laboratory under contract \# S006987-R through US ITER Project and USITER 15300-PD0002R00. The work performed in support of this report was made possible by the United States Department of Energy through PPPL Prime Contract Number DE-AC02-09CH11466

\section{REFERENCES}

[1] See ITER_D_27ZRW8 - Project Requirements (PR)

[2] "EP09 Internal Interfaces Technical Note”, ITER_D_AQJN62 v1.1, Section 5.5, page 27.

[3] "ANNEX B3 To Procurement Arrangement 5.5.P4.US.01 between the ITER International Fusion Energy Organization and The Domestic Agency of the United States of America For the supply of Equatorial Port\#9 Engineering”, ITER_D_BNDFHk_v1_3, page 34

[4] Mahmoud .Z. Youssef, Russell Feder, "Summary Of The Up-To-Date 3D Nuclear Analyses Of ITER Diagnostics Generic Equarorial Port Plug (GEPP) Performed With The ATTILA Design Code", Proceedings of the 20th Symposium on the Technology of Fusion Energy, TOFE-20, August 27-31, 2012, Nashville, TN, USA. To appear in Fus. Sci. Technol. (2013)

[5] M.Z.Youssef, R.Feder, "Global dose rate assessment in ITER diagnostics ports based on the 3-D FEM ATTILA code", Fusion Eng. Des., 87, Issues 7-8, 1101-1110 (August 2012)

[6] R. Feder, M.Z. Youssef, "Survey of Interspace Dose Rates for USITER Equatorial Port Diagnostics," USITER report, 1050308-RP0001-R00, PA/TA No: PA 5.5.P4.US.01, (February 2013)

[7] A. Serikov, et al. ,"Neutronics for equatorial and upper ports in ITER", 27th Symposium on Fusion Technology, SOFT-2012, September 24-28, 2012, Liege, Belgium (2012)

[8] ATTILA: Comprehensive Radiation Transport Solution Environment, http://www.transpireinc.com/, Transpire Inc

[9] M.Z.Youssef, R.Feder, "Benchmarking of the 3-D CAD-Based Discrete Ordinates Code"Attila" for dose rate calculations against experiments and Monte Carlo calculationsExperimental", Presented at the $27^{\text {th }}$ Symposium on Fusion Technology, SOFT-27, September 24-28, 2012, Liege, Belgium, (2012). To appear in Fus. Eng. Des. (2013)

[10] M.J. Loughlin and N.P. Taylor, "Recommended Plasma Scenarios for Activation Calculations", ITER_D_2V3V8G v 1.0, IDM ITER Document, October, (2009)

[11] R. Pampin et al. "Radiation transport analysis for ITER core LIDAR diagnostic", Fus. Sci. Technology Journal , 56, (2009)

[12] R. Pampin, "Radiation transport analyses supporting ITER core LIDAR system design", Euratom/UKAEA Fusion Association, Culham Science Centre, Abingdon OX14 3DB, UK, TW6-TPDS-DIADES TSCL (EFDA/06.1450) WP 1.2.3.0.0, Final report, January 2008 